\title{
Note: Optical fiber milled by focused ion beam and its application for Fabry-Pérot refractive index sensor
}

\author{
Yuan, Scott Wu; Wang, Fei; Savenko, Alexey; Petersen, Dirch Hjorth; Bang, Ole
}

Published in:

Review of Scientific Instruments

Link to article, DOI:

$10.1063 / 1.3608111$

Publication date:

2011

Document Version

Publisher's PDF, also known as Version of record

Link back to DTU Orbit

Citation (APA):

Yuan, S. W., Wang, F., Savenko, A., Petersen, D. H., \& Bang, O. (2011). Note: Optical fiber milled by focused ion beam and its application for Fabry-Pérot refractive index sensor. Review of Scientific Instruments, 82(7), 076103. https://doi.org/10.1063/1.3608111

\section{General rights}

Copyright and moral rights for the publications made accessible in the public portal are retained by the authors and/or other copyright owners and it is a condition of accessing publications that users recognise and abide by the legal requirements associated with these rights.

- Users may download and print one copy of any publication from the public portal for the purpose of private study or research.

- You may not further distribute the material or use it for any profit-making activity or commercial gain

- You may freely distribute the URL identifying the publication in the public portal 


\title{
Note: Optical fiber milled by focused ion beam and its application for Fabry-Pérot refractive index sensor
}

\author{
Wu Yuan, ${ }^{1}$ Fei Wang, ${ }^{2, a)}$ Alexey Savenko, ${ }^{2}$ Dirch Hjorth Petersen, ${ }^{2}$ and Ole Bang ${ }^{1}$ \\ ${ }^{1}$ Department of Photonics Engineering, Technical University of Denmark, DK-2800 Kgs. Lyngby, Denmark \\ ${ }^{2}$ Department of Micro- and Nanotechnology, Technical University of Denmark, DK-2800 Kgs. Lyngby, \\ Denmark
}

(Received 17 April 2011; accepted 11 June 2011; published online 15 July 2011)

\begin{abstract}
We introduce a highly compact fiber-optic Fabry-Pérot refractive index sensor integrated with a fluid channel that is fabricated directly near the tip of a $32 \mu \mathrm{m}$ in diameter single-mode fiber taper. The focused ion beam technique is used to efficiently mill the microcavity from the fiber side and finely polish the end facets of the cavity with a high spatial resolution. It is found that a fringe visibility of over $15 \mathrm{~dB}$ can be achieved and that the sensor has a sensitivity of $\sim 1731 \mathrm{~nm} / \mathrm{RIU}$ (refractive index units) and a detection limit of $\sim 5.78 \times 10^{-6}$ RIU. This miniature integrated all-in-fiber optofludic sensor may find use in minimal-invasive biomedical applications. (C) 2011 American Institute of Physics. [doi:10.1063/1.3608111]
\end{abstract}

Fiber-optic Fabry-Pérot (FP) sensors are widely used for the measurement of a variety of physical parameters, such as pressure, strain, and temperature, with high sensitivity and accuracy. ${ }^{1-4}$ They are typically made with a sealed cavity in the fiber. However, when exposed to the external environment, a FP cavity can also be used to measure the refractive index (RI) of a fluid with a linear response by tracking the phase shift of the interference signal. This microfluidic fiber device is based on an effective overlap between the optical field and the fluid in the cavity. For a guided mode the interaction with the fluid can be maximized when both the light and the fluid are confined simultaneously in the waveguide core. Such assembly is desirable for achieving a large dynamic response range and short interaction length. Practical implementations to realize such FP microfluidic sensors have relied on abutting two fiber surfaces to the microfluidic channel, ${ }^{5}$ while other proposed techniques involve placing two fibers with polished end facets a certain distance apart in a sleeving tube or coupling fibers into a hollow-core planar waveguide. ${ }^{6,7}$

An alternative method is considered here, where the microfluidic cavity is fabricated directly into an optical fiber so as to achieve an improved channel integration, reliability, and ease of production. As a result, the desired alignment, and hence the interaction between the microfluidic channel and the optical waveguide, can be accurately defined. The fiber constitutes the backbone conduit for light guiding, and effective light-fluid interaction is achieved when the microfluidic channel intersects the optical pathway. In recent years, devices such as microchannels, microslots, and FP interferometers have been fabricated in single-mode fibers (SMFs) by the use of femtosecond laser micromachining, ${ }^{8-12}$ which can be effectively utilized for RI sensing with low temperature sensitivity and large dynamic range. However, a relative low fringe visibility of the interference pattern is achieved when using this technique for making FP fiber sensors. An

a) Author to whom correspondence should be addressed. Electronic mail: Fei.Wang@ nanotech.dtu.dk. additional chemical etching processing is needed to remove sputtered remains adhering to the surface of the cavity and a shorter laser wavelength should be used to achieve a better surface roughness in order to improve the fringe visibility. ${ }^{13}$

In this paper, we describe an alternative approach based on ion beam micromachining. Focused ion beam (FIB) has been used in a number of fiber-based applications, including fabrication of long period gratings, ${ }^{14}$ micromachining of fiber tips ${ }^{15}$ and milling of side access holes in structured optical fibers. ${ }^{16}$ As a consequence of its applications in semiconductor technology, the FIB technique is mature and much more flexible than the femtosecond laser processing, and dualbeam instruments combining a scanning electron microscope (SEM) and FIB are commercially available nowadays. Here, we use a commercial FIB system to fabricate a compact infiber FP RI sensor by creating a side accessed microcavity in a conventional SMF taper with sub-micrometer spatial resolution. This method has the advantage of allowing micromachining with more well defined milling profiles and a better surface finishing than what can be obtained with femtosecond laser technology with the conventional $800 \mathrm{~nm}$ wavelength, without the requirements of additional etching steps.

A Quanta 200 3D FIB with $\mathrm{Ga}+$ ion source is used to mill the fiber. The use of the FIB as a milling tool allows quick and direct patterning via a sputtering process. During sputtering, a portion of the ejected atoms or molecules are redeposited on the exposed region, making it difficult to control the amount of material that is removed. In order to avoid this redeposition process, the fiber is perpendicularly aligned with the ion beam and the milling process starts from the fiber side so that a pathway will be formed for the material ejection. Furthermore, a high incident angle (close to $90^{\circ}$ ) of the ion beam can speed up the milling rate significantly, since the FIB sputtering yield roughly increases with $1 / \cos (\theta)$, where $\theta$ is the angle between the surface normal and the FIB direction. ${ }^{17}$

During the ion bombardment process, there are excess charges cumulated on the surface of the material. These charges will cause random deflection of the incident ion beam 


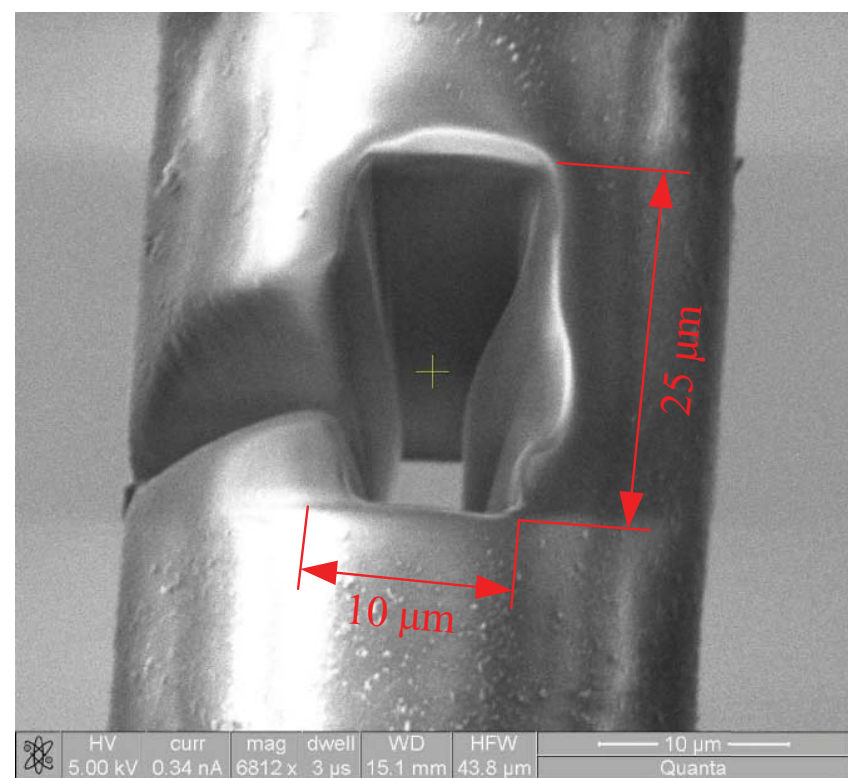

FIG. 1. (Color online) SEM image of the milled micro-cavity in the $32 \mu \mathrm{m}$ in diameter fiber taper.

and thus damage the milling profile. To avoid the charging effect, the fiber is fixed on the top of conductive carbon tape that is attached to the grounded sample holder. Moreover, a charge neutralization process with the aid of an electron beam is applied to counteract the charges. A conductive metal wire is also coiled as an anchor to prevent the fiber from vibrating. The micromachining is performed as close as possible to the anchored point.

To make a compact FP fiber sensor, a conventional SMF is used. The diameter of the fiber is tapered down to $32 \mu \mathrm{m}$ to reduce the amount of surrounding silica that the FIB needs to penetrate before accessing the fiber core. This assists in reducing the milling time. To obtain a high milling rate, a high ion current of $20 \mathrm{nA}$ is used at the beginning, which gives a relatively large beam spot size of $0.3-0.5 \mu \mathrm{m}$. As shown in Fig. 1, the FIB milling starts from the side of the fiber to make an opening for the material ejection and reduce the material redeposition. After the speedy milling, a lower ion current ( $3 \mathrm{nA}$ ) is used to polish the two ends of the cavity with higher spatial resolution (down to $10 \mathrm{~nm}$ ). A small additional tilt of the fiber $\left(\sim 3^{\circ}\right)$ to the incident direction of the ion beam is applied during the polish milling, in order to get rid of the residual angle misalignment during milling on a tangent and obtain parallel end walls of the microcavity. In this way a $25 \mu \mathrm{m}$ long microcavity with a width of $10 \mu \mathrm{m}$ is fabricated in the core of the fiber. The whole milling process takes around 20 minutes. The finely milled end facets of the microcavity can be seen in the enlarged SEM image in Fig. 1. It is clearly seen that the inner sidewalls of the microcavity are not perfectly parallel, since $3 \sim 7$ degree angle misalignment occurs due to the convergence of the FIB. This will not have a noticeable negative influence on the performance of the FP fiber sensor, since the surface quality of the end facets of the microcavity will have a much stronger influence on the interference pattern.

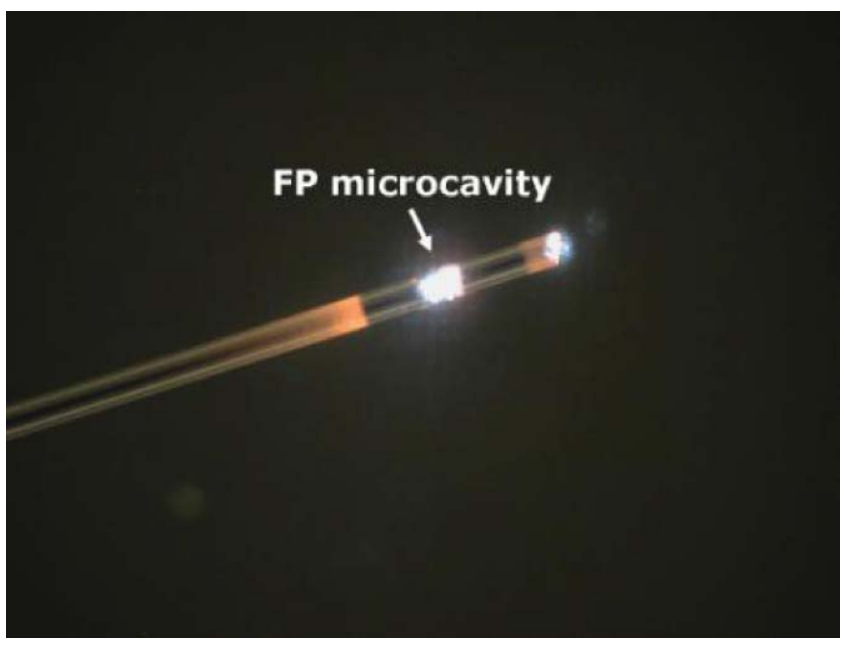

FIG. 2. (Color online) Microscope image of the light guided in a $\sim 500 \mu \mathrm{m}$ long fiber taper with the FP microcavity and the shattered fiber end.

The microcavity is milled near the tip of the fiber taper and the taper end is shattered in order to reduce the Fresnel reflection, as shown in the Fig. 2. An experiment is carried out to test this microcavity as a FP fiber sensor. The fiber is spliced to a SMF28 and connected to a circulator. A tunable laser source (Ando, AQ4321D) with output from 1520 $\mathrm{nm}$ to $1620 \mathrm{~nm}$ is used to pump the fiber and synchronized with an OSA (Ando, AQ6317B), which is used to record the reflection spectrum. The fiber sensor is then immersed in a refractive index liquid (Cargille, RI = 1.3 @ $589.3 \mathrm{~nm}$ and $25{ }^{\circ} \mathrm{C}$ ) which has a negative thermal coefficient, i.e., $\mathrm{dn} / \mathrm{dT}$ $\approx-3.4 \times 10^{-4} /{ }^{\circ} \mathrm{C}$. A resistive hot stage (MC60+TH60, Linkam) is used to heat up the liquid from $25^{\circ} \mathrm{C}$ to $63.8^{\circ} \mathrm{C}$. A thermo couple is used to measure the temperature as close to the microcavity as possible with a resolution around $0.1{ }^{\circ} \mathrm{C}$.

As shown in Fig. 3, a FP interference pattern with an extinction ratio of about $15 \mathrm{~dB}$ and a pitch of about $37.4 \mathrm{~nm}$ is generated. Estimated with the wavelength of $\lambda_{v 1}$ and $\lambda_{v 2}$,

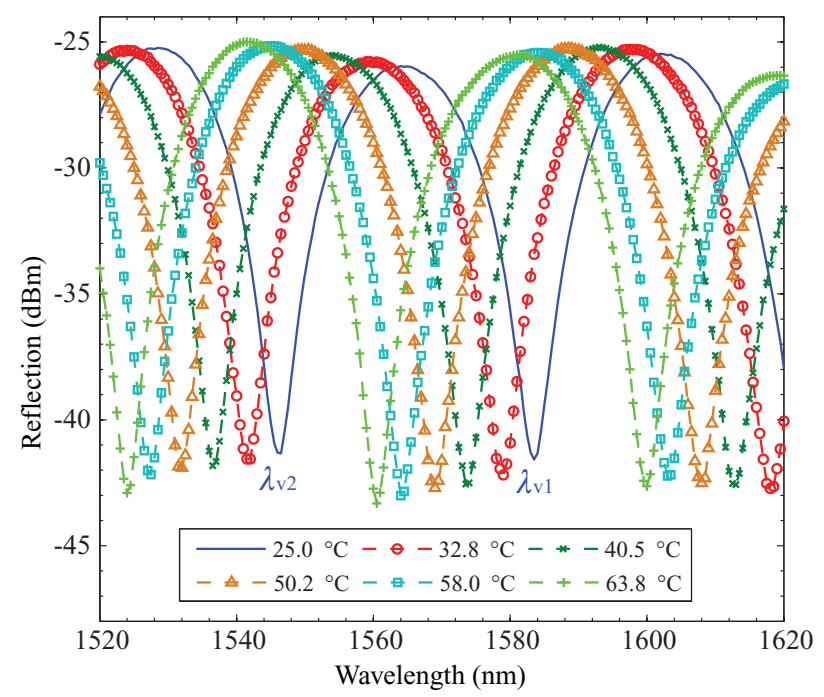

FIG. 3. (Color online) FP reflection spectrum for different temperatures of the refractive index liquid. 


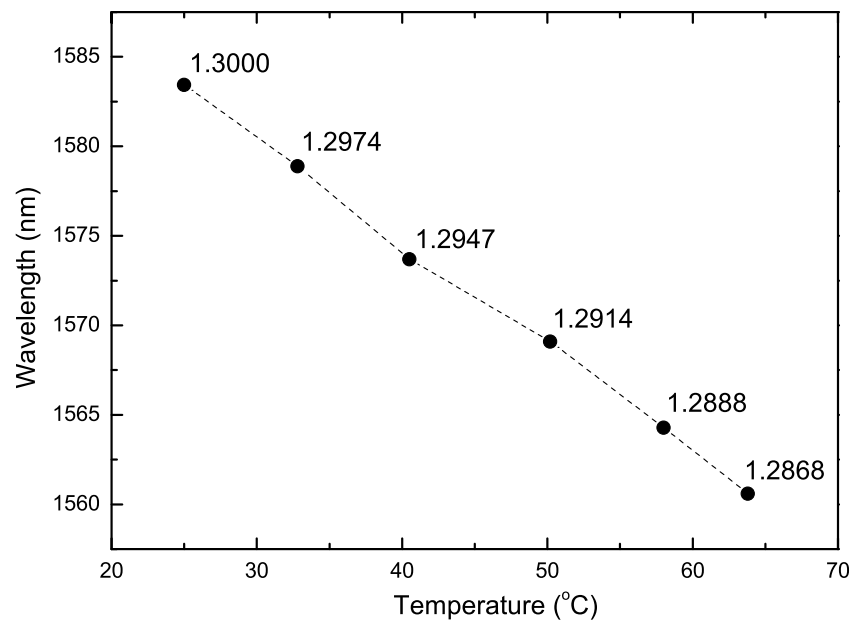

FIG. 4. Shift of $\lambda_{v 1}$ vs. temperature, labeled numbers indicate the estimated refractive indices.

i.e., $\lambda_{v 1}=1583.45 \mathrm{~nm}$ and $\lambda_{v 2}=1546.05 \mathrm{~nm}$, and using the factory defined refractive index value of the liquid at 25 ${ }^{\circ} \mathrm{C}$, i.e., $\mathrm{n}=1.3$, a $25.274 \mu \mathrm{m}$ FP cavity and a pitch of $37.28 \mathrm{~nm}$ are obtained from the relation $4 \mathrm{~nL}=\mathrm{m} \lambda_{v}$, where $\mathrm{m}$ is an odd integer, which is 83 for $\lambda_{v 1}$ and 85 for $\lambda_{v 2}$. The whole spectrum shifts linearly towards shorter wavelength with increased temperature. An increased extinction ratio is also observed, which is due to the decrease in the refractive index of the liquid and the corresponding increase of the Fresnel reflection at the silica/liquid interface. By tracking $\lambda_{v 1}$ as shown in Fig. 4, a total shift of $22.85 \mathrm{~nm}$ was introduced by a temperature increase of $38.8^{\circ} \mathrm{C}$, which corresponds to an estimated decrease in the refractive index by $1.32 \times 10^{-2}$. This leads to a sensitivity of $\sim 1731 \mathrm{~nm} / \mathrm{RIU}$. Taking into account the OSA resolution of $0.01 \mathrm{~nm}$, the FP fiber sensor has a detection limit of $\sim 5.78 \times 10^{-6}$ RIU. The Q value of this sensor is about 500 . It is important to note that the $\mathrm{Q}$ value and the sensitivity of the FP sensor are proportional to the length of the FP cavity and can be easily improved by using a longer cavity.

In summary, we have demonstrated micromachining of a highly compact fiber-optic FP RI sensor in a conventional SMF taper by using FIB. Measures taken to avoid the redeposition and counter charge accumulation can effectively speed up the milling rate and give a well defined microcavity profile. The reflection spectrum of such a device with a $25 \mu \mathrm{m}$ long microcavity infiltrated with a refractive index liquid has been investigated and thermally tuned. As a result of the tapering, both the guiding loss and the coupling loss of the light reflected from the second end facet of the FP cavity back into the fiber core increased significantly. Taking these factors into account, a fringe visibility exceeding $15 \mathrm{~dB}$ provided by our sensor is still better than what can be achieved by most FP sensors fabricated in untapered fibers by femtosecond lasers and other techniques, which is usually less than $15 \mathrm{~dB} \cdot{ }^{1-7,10-12}$ This improved fringe visibility is mainly due to the finely polished end facets and precisely milled parallel two end walls of the microcavity. A sensitivity of $\sim 1731 \mathrm{~nm} / \mathrm{RIU}$ and a detection limit of $\sim 5.78 \times 10^{-6}$ RIU can be achieved, which is comparable to the FP sensitivity reported by other groups $^{1-7,10-12}$ and exceeds the $1500 \mathrm{~nm} / \mathrm{RIU}$ demonstrated for long period grating based RI sensors in PCFs. ${ }^{18}$ It is still a long way from the $70000 \mathrm{~nm} / \mathrm{RIU}$ predicted for two-core PCF coupler based RI sensors, ${ }^{19,20}$ but the FP technology in standard SMF is more simple and robust.

We would like to acknowledge support from the Danish National Advanced Technology Foundation (Project No. 10080864). The FIB fabrication process was performed at the Center for Electron Nanoscopy (DTU CEN).

${ }^{1}$ Y. J. Rao, Opt. Fiber Technol. 12, 227 (2006).

${ }^{2}$ Y. Zhu and A. Wang, IEEE Photon. Technol. Lett. 17, 447 (2005).

${ }^{3}$ H. Xiao, J. Deng, G. Pickrell, R. G. May, and A. Wang, J. Lightwave Technol. 21, 2276 (2003).

${ }^{4}$ Y. Zhang, X. Chen, Y. Wang, K. L. Cooper, and A. Wang, J. Lightwave Technol. 25, 1797 (2007).

${ }^{5}$ P. Domachuk, I. C. M. Littler, M. Cronin-Golomb, and B. J. Eggleton, Appl. Phys. Lett. 88, 093513 (2006).

${ }^{6}$ S. Campopiano, R. Bernini, L. Zeni, and P. M. Sarro, Opt. Lett. 29, 1894 (2004).

${ }^{7}$ G. Z. Xiao, A. Adnet, Z. Y. Zhang, F. G. Sun, and C. P. Grover, Sens. Actuators, A 118, 177 (2005).

${ }^{8}$ Y. Lai, K. Zhou, L. Zhang, and I. Bennion, Opt. Lett. 31, 2559 (2006).

${ }^{9}$ K. Zhou, Y. Lai, X. Chen, K. Sugden, L. Zhang, and I. Bennion, Opt. Express 15, 15848 (2007)

${ }^{10}$ Z. L. Ran, Y. J. Rao, W. J. Liu, X. Liao, and K. S. Chiang, Opt. Express 16, 2252 (2008)

${ }^{11}$ T. Wei, Y. Han, H. Tsai, and H. Xiao, Opt. Lett. 33, 536 (2008).

${ }^{12}$ T. Wei, Y. Han, Y. Li, H. Tsai, and H. Xiao, Opt. Express 16, 5764 (2008).

${ }^{13}$ Z. L. Ran, Y. J. Rao, H. Y. Deng, and X. Liao, Opt. Lett. 32, 3071 (2007).

${ }^{14}$ C. Martelli, P. Olivero, J. Canning, N. Groothoff, S. Prawer, S. Huntington, and B. Gibson, OSA/BGPP, BTuC6 (2007).

${ }^{15}$ B. C. Gibson, S. Huntington, S. Rubanov, P. Olivero, K. DigweedLyytikäinen, J. Canning, and J. D. Love, Opt. Express. 13, 9023 (2005).

${ }^{16}$ C. Martelli, P. Olivero, J. Canning, N. Groothoff, B. Gibson, and S. Huntington, Opt. Lett. 32, 1575 (2007).

${ }^{17}$ S. Reyntjens and R. Puers, J. Micromech. Microeng. 11, 287 (2001).

${ }^{18}$ L. Rindorf and O. Bang, Opt. Lett. 33, 563 (2008).

${ }^{19}$ G. E. Town, W. Yuan, R. McCoster, and O. Bang, Opt. Lett. 35, 856 (2010).

${ }^{20}$ W. Yuan, G. E. Town, and O. Bang, IEEE Sens. J. 10, 1192 (2010). 